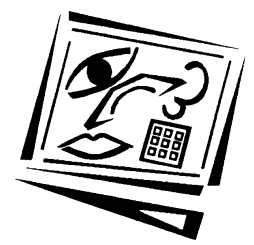

\title{
Implementing a self-regulated WebQuest learning system for Chinese elementary schools
}

\author{
Hsien-Sheng Hsiao, Chung-Chieh Tsai, Chien-Yu Lin and Chih-Cheng Lin \\ National Taiwan Normal University
}

\begin{abstract}
The rapid growth of Internet has resulted in the rise of WebQuest learning recently. Teachers encourage students to participate in the searching for knowledge on different topics. When using WebQuest, students' self-regulation is often the key to successful learning. Therefore, this study establishes a self-regulated learning system to assist learners in employing WebQuest learning in a self-regulated learning pattern as well as to give teachers opportunities to monitor and assist students' performance. The participants in the study are sixth graders of an elementary school in Taipei County, Taiwan. The experimental group and the control group are composed of three classes respectively. The current study investigates the correlation between students' selfregulated behavior and their achievement when using WebQuest learning through the self-regulated learning assisted functions and traditional WebQuest learning. In addition, learners' self-regulated behavior is observed and analysed based on the system records as well as their behaviour in the learning process.
\end{abstract}

\section{Introduction}

The impact and influence of the Internet and world wide web can be best described by Bill Gates's statement: information at your fingertips. The Internet has now become one of the most popular media types. Learners obtain knowledge not only from teachers but also search for information on the Internet, asking questions and leaving messages, as well as sharing their ideas with others. Dodge (1995) defines WebQuest as an inquiry activity designed for learners to share part or all the information on the Internet, which corresponds to many Internet users' utilisation of search engines such as Yahoo and Google.

The main idea of WebQuests is that learners can obtain information from online documents and online databases, and all the resources on the Internet are their learning materials (Dodge, 2002; WebQuest, 2007). In recent years, WebQuests have been applied extensively to various educational environments. Computer-supported systems are designed to offer not only a structured discussion and debate space but also the navigation and resource sharing in a WebQuest learning process (Belgiorno, Malandrino, Manno, Palmieri \& Scarano, 2009; Zacharia, Xenofontos \& Manoli, 2011). Çigrik and Ergül (2010) indicate that WebQuests can improve logical thinking ability in science education. Furthermore, WebQuests also support the construction of creative learning systems (Sanford, Townsend-Rocchiccioli, Trimm \& Jacob, 2010). In a sheltered Internet environment, the close-search condition provided by a WebQuest can improve learning gains and writing quality (Segers \& Verhoeven, 2009). As for higher education, Allan and Street (2007) integrated a knowledge-pooling stage into a 
WebQuest in initial teacher training. In addition to traditional Internet environments, WebQuests are also applied to new learning environments. Web 2.0 tools, such as blogs and online chat extend traditional WebQuest learning opportunities (Kurt, 2010). Chang, Chen \& Hsu (2010) also integrated WebQuest with mobile learning for environmental education. They introduced the WebQuest into outdoor instruction by using a PDA (personal digital assistant) as a learning tool. The above-mentioned studies show that using WebQuests in various learning environments influences learners' learning performance positively.

However, some studies argue that learners may become lost in the abundant resources on the Internet, and may waste time when using it without goals. Dodge states that the efficacy of education is questionable when learners use the Internet aimlessly. Thus, some researchers suggest that teachers should select appropriate websites for students and guide the students to use them (Cartwright, 2005; Dodge, 2002). Some studies also point out that although WebQuests can improve the development of critical thinking, it does not improve the learning effect. In other words, beneficial learning information is important to the learning effect, and so is the teachers' guidance. Self-regulated learning patterns can improve learning outcomes, and enhance learners' awareness of self-efficacy and learning autonomy (Zimmerman, Bonner \& Kovach, 1996). If students can control and examine their own learning routes, with the teacher's assistance, in self-regulated learning patterns, can they identify appropriate websites on their own? Thus, it is suggested that future research should further investigate the influence of guidance towards self-regulated learning upon learning material searches.

The principles of WebQuest proposed by Dodge (2001) incorporate inquiry-oriented and collaborative learning. Dodge also claims that scaffolding in WebQuest helps information analysis, integration, and interaction (Dodge, 2001). Scaffolding can help learners go beyond their current level and display their learning activities clearly. Dodge suggests that teachers help learners construct basic concepts with scaffolding, and guide them to focus on, organise, and record observed information, as well as cultivate good learning habits in WebQuest. However, Vygotsky's zone of proximal development concept indicates that scaffolding is constructed between learners' current intellectual level and latency ability, so that they can solve problems with the help of adults or peers (Vygotsky, 1978). As this distance is not necessarily the same for every peer, assistance by scaffolding for each learner in the process of WebQuests is important. Many researchers indicate that learners can have productive learning attitudes through self-regulated learning and scaffolding approaches (Azevedo \& Cromley, 2004; Butler \& Cartier, 2005; Shih, Chen, Chang \& Kao, 2010). Therefore, the current study attempts to investigate correlation between students' self-regulated level and their learning outcomes from WebQuest learning with self-regulated learning assisted functions. Issues concerning collaborative learning in WebQuest learning are not emphasised in this study.

This research develops self-regulated learning assisted functions, including selfevaluation and monitoring, goal setting and strategic planning, strategic implementation and monitoring, and strategic outcome monitoring, as proposed by Zimmerman et al. (1996), for WebQuest learning. The participants in this study are sixth graders who proceeded to WebQuest learning on the topic of environmental protection soap, and they make use of the learning records in the system. We examine whether or not self-regulated learning assisted functions in WebQuest learning can enhance learning outcomes. Also, researchers' observation and system recording are scrutinised to investigate learners' 
self-regulated behaviour in the learning process. Based on the rationale mentioned above, the research aims to identify learning outcomes in WebQuest learning with selfregulated learning assisted functions. Learning outcomes are students' learning achievements and their self-regulated behaviour in the learning process. The study uses both qualitative and quantitative approaches, with research questions:

1. Establish a WebQuest learning system with self-regulated learning assisted functions;

2. Investigate differences between students' learning outcomes from WebQuest learning with self-regulated learning assisted functions, and from traditional WebQuest learning;

3. Compare students' self-regulated behaviour from WebQuest learning with selfregulated learning assisted functions, and from traditional WebQuest learning.

\section{System implementation}

The self-regulated learning assisted functions for WebQuest learning developed in this study are based on the design procedures proposed by Dodge (1995), which includes six steps: Introduction, Task, Process, Resources, Evaluation, and Conclusion. The teaching material part is displayed as the search results provided by the system. The task design checking sheet for WebQuest follows the task classification proposed by Dodge (2002) and other relevant literature, so as to scrutinise the construction of the assisted functions and teaching system. In addition, each function for assisting learners' selfregulation is based on the theory of self-regulated learning cycle model (Zimmerman et al., 1996), as shown in Figure 1. There are four interrelated steps in the cycle that help students evaluate their performance. With the model, students can plan their learning schedule by themselves according to these steps. Details of the system implementation are presented as follows.

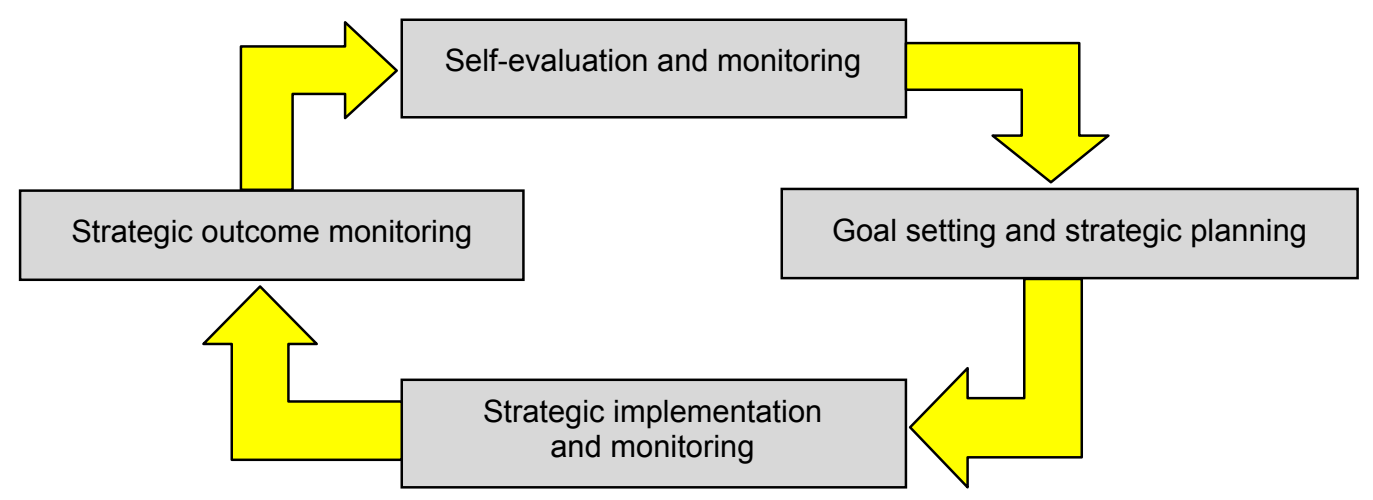

Figure 1: Self-regulated learning cycle model

\section{System architecture}

The proposed system contains a student usage subsystem and a teacher management subsystem, as shown in Figures 2 and 3. The student usage subsystem offers the WebQuest learning and the self-regulated learning assisted functions. The subsystem includes WebQuest learning platform, discussion platform, and self-regulated learning 
assisted platform. The goal of the WebQuest learning platform is to provide the WebQuest learning environment. The platform has four functions, namely WebQuest introduction, WebQuest task description, Website search interface and WebQuest learning area, which is composed of the six steps in WebQuest. The discussion platform provides the functions of sharing between the teacher and students. The sharing functions include personal learning blogs that record what students have learned, chat rooms that provide the communication area for the teacher and students, and a learning website recommendation function that can be used by students to recommend new websites to other students. The self-regulated learning assisted platform offers the self-regulated assisted functions for students to monitor their learning processes. This platform includes self-regulated learning record function, WebQuest learning system record function, and teacher-student interactive function.

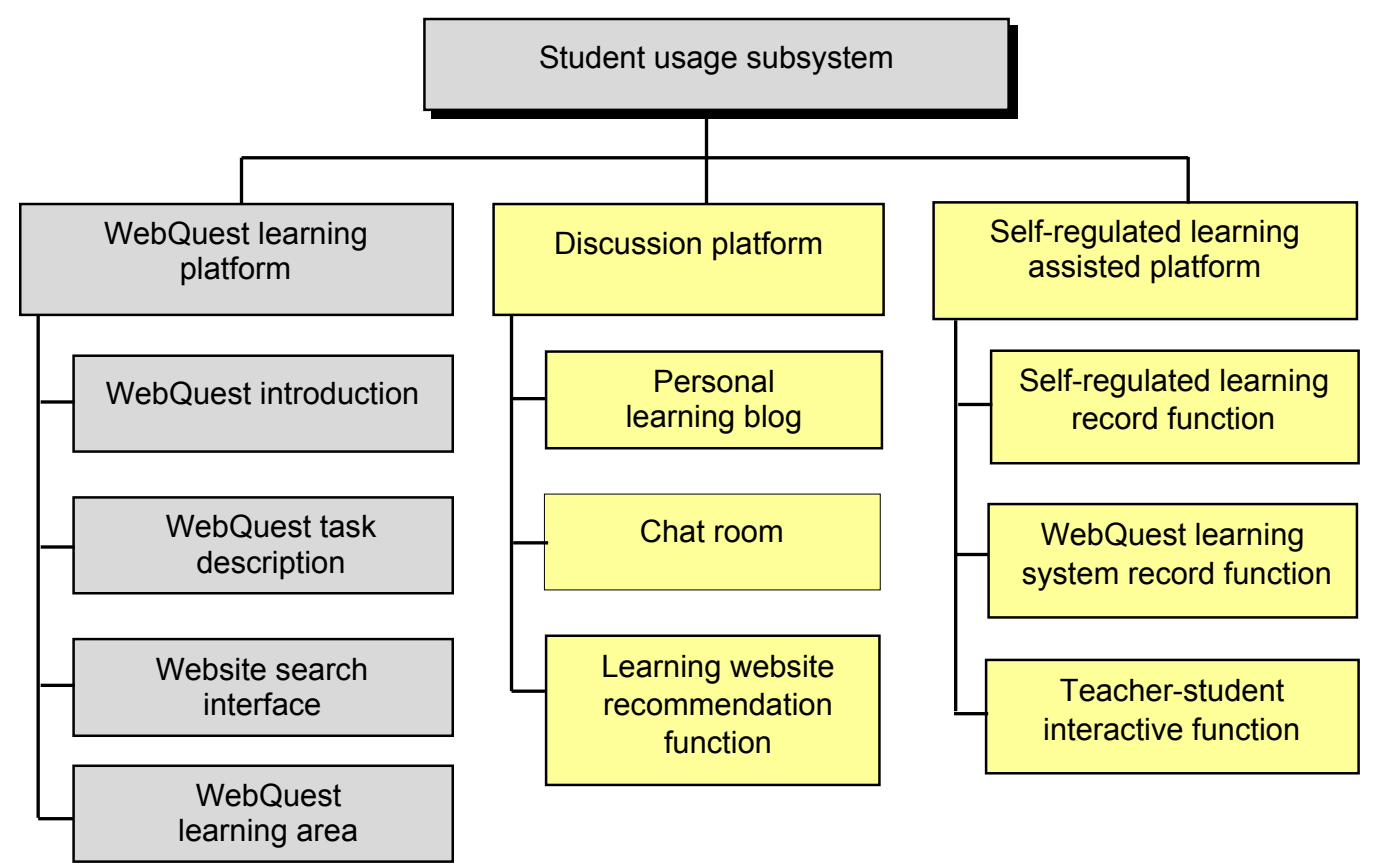

Figure 2: Student usage subsystem structure

The teacher management subsystem (Figure 3) provides monitoring functions for the teacher, including WebQuest management platform, communication platform, and monitoring learning platform. The teacher can use the WebQuest management platform to prepare WebQuest learning activities. The communication platform provides the sharing and real time communication functions. During the learning process, the teacher can monitor the self-regulated learning status of the students via the monitoring learning platform.

The traditional WebQuest learning system used by the control group also includes student usage subsystem and teacher management subsystem. However, in the traditional WebQuest learning system, the student usage subsystem and the teacher management subsystem only offers the WebQuest learning platform and the WebQuest management platform respectively (the grey parts shown in Figures 2 and 3). In other 
words, the system used by the control group does not provide the self-regulated assisted functions for WebQuest learning activities.

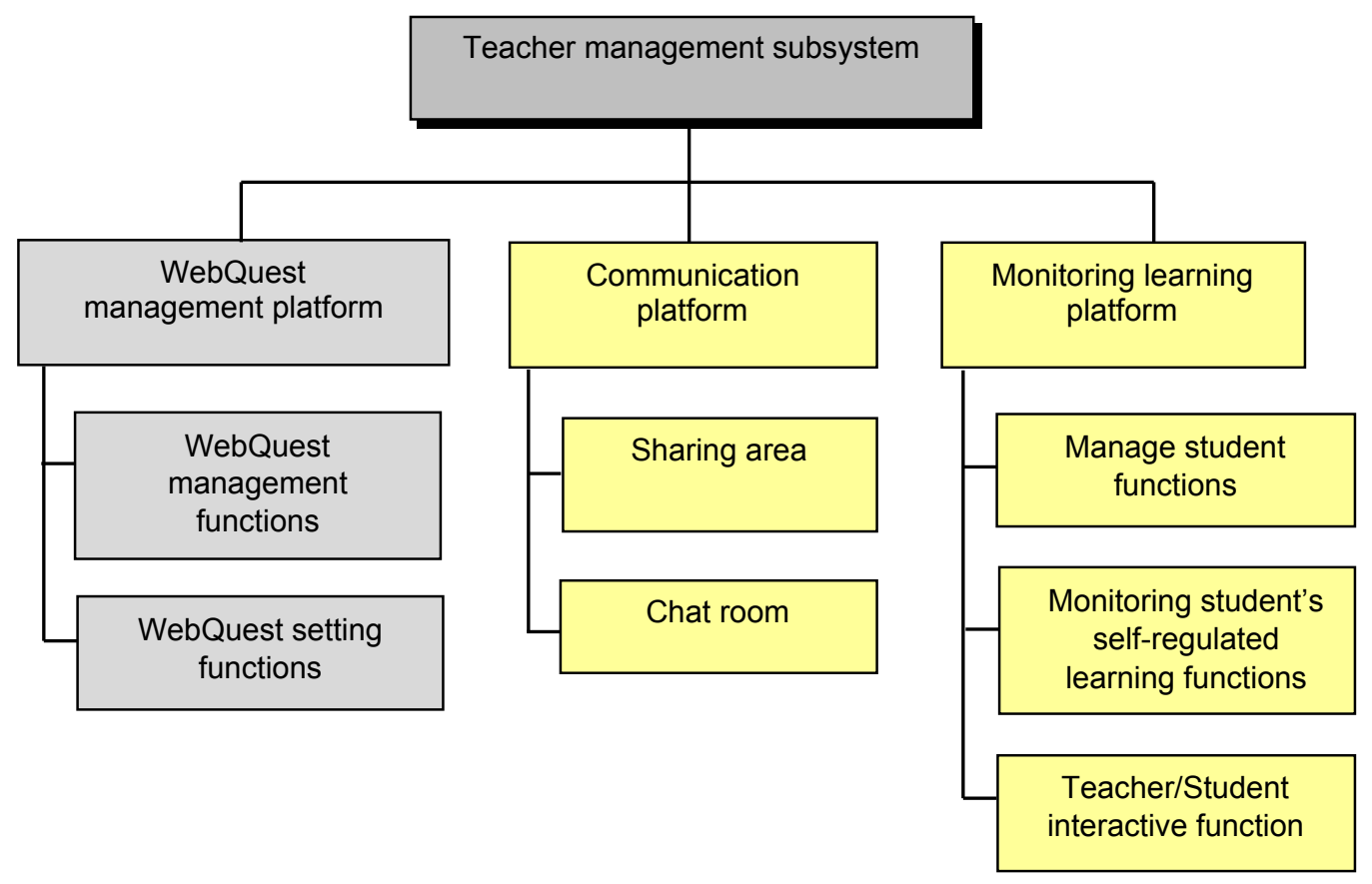

Figure 3: Teacher management subsystem structure

\section{System usage flow}

This study was based on a five-week period with each week having an inquiry task to be completed by the students. The flow of the system used in each task is presented in the following phases. In the preparing phase of teaching, the teacher prepares for the arrangement of WebQuest learning, including the design of tasks and periodical assignments, and also sets the learning expectation for learners. During a learning activity, the students can be assisted by the proposed system to process the WebQuest learning task, as shown in Figure 4. The flow of system usage is described as follows.

1. After system training and manual details noting, students proceed to WebQuest learning based on the instruction.

2. Teachers stay online to give necessary assistance to students on different levels.

3. In the weekly task, students can record and share their learning experience online, and teachers can elicit different ways of thinking as well as further inquiry, which is the phase of strategy implementation and monitoring in the self-regulated learning cycle.

4. Teachers and students can give suggestions, feedback, and evaluation in the system as a basis for further modification, which is the phase of strategic outcome monitoring in the self-regulated learning cycle.

5. After getting the scores of their learning history, students write down their learning situations and future modification with discussions with teachers. Later, students 
fill out the goal setting sheet, and teachers provide necessary help based on the sheet. This is the phase of self-evaluation and monitoring, and goal setting and strategic planning in the self-regulated learning cycle.

6. Teachers can adjust the tasks based on learners' learning situations.

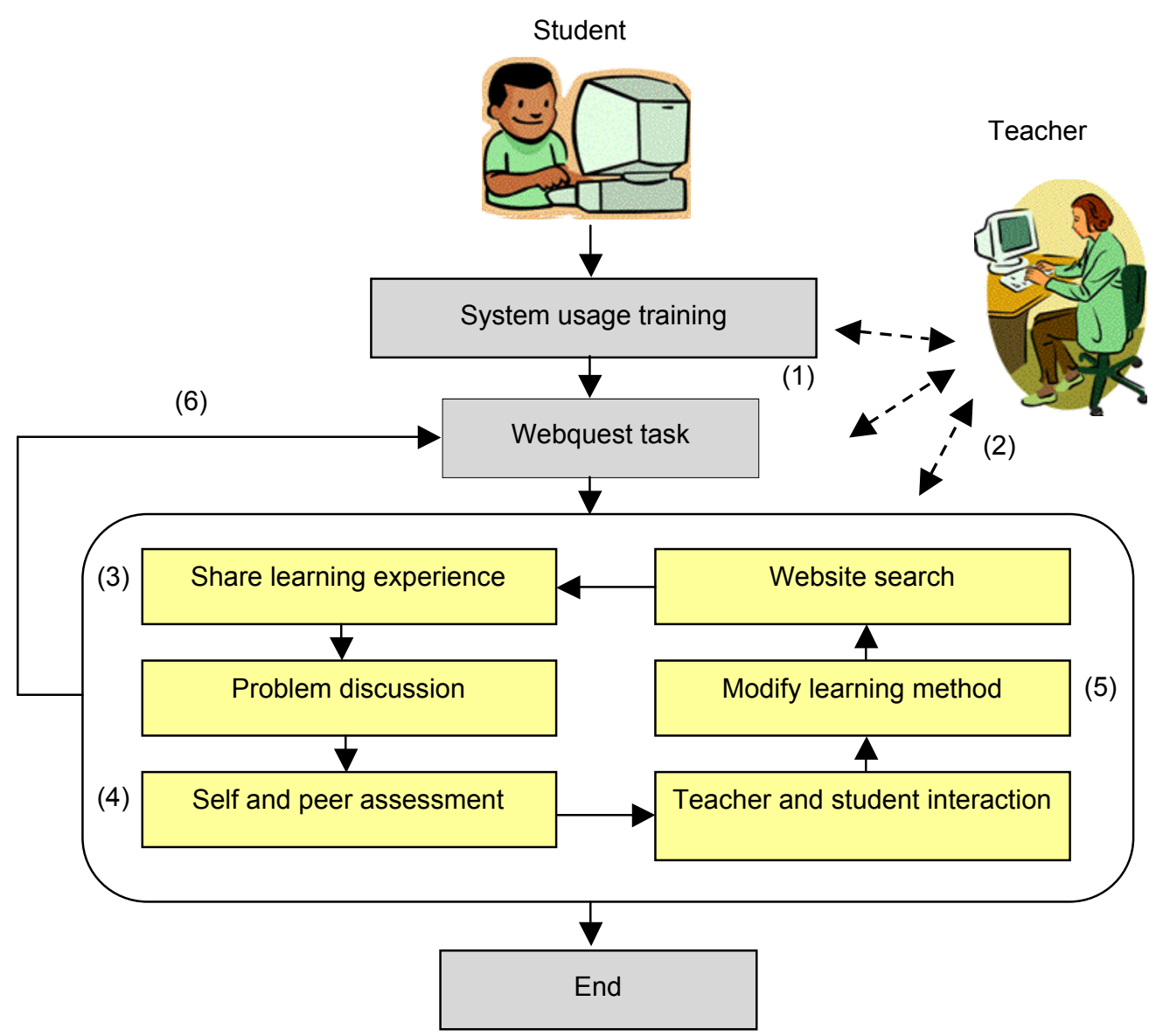

Figure 4: The flow of system usage

\section{Self-regulated functions}

The study developed the system based on the self-regulated learning cycle model, with the functions of self-regulation defined as follows.

Self-evaluation and monitoring

After logging onto the system, learners can see the goal of the weekly task (Figure 5). In the task check module, learners understand the goal and content of the task in the Task item, view assignment regulation in the Evaluation item, and understand the meaning of the task in the Conclusion item. Later, students are asked to fill out the goal setting sheet (Figure 6) after they understand the knowledge content and level. 


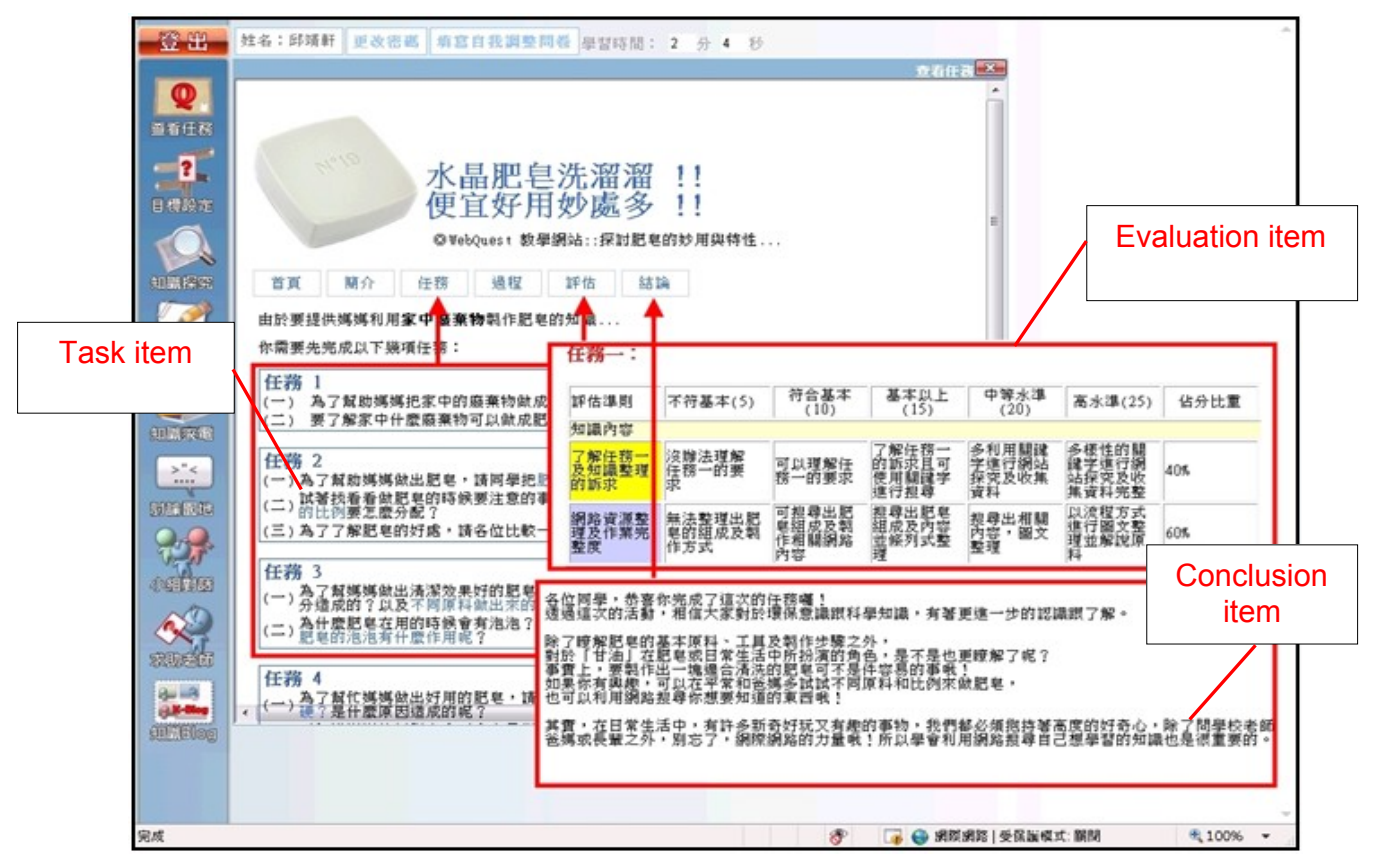

Figure 5: Login screen and inquiry task

Goal setting and strategic planning

A learning activity is divided into six items, based on teachers' prepared teaching content, including knowledge, assignment, sharing, time, interaction, and adjustment. The learning history is recorded for these six items. Once students understand the purpose of each task, they fill out a learning activities goal setting sheet that contains eight items (Figure 6). Being transformed by the system, their learning situations are indicated in the red area of the radar chart in Figure 7, showing the expected scores set by each student. The score chosen for the first question in Figure 6 is the expected total score for each weekly task, while the score in the second question is learners' organisation of their own knowledge in articles, or their survey of articles by their peers, corresponding to the scores of knowledge in the radar chart. The score in the third question corresponds to that of assignments, showing their weekly assignment scores, and the score in the fourth question corresponds to that of sharing, indicating learners' sharing of articles and feedback. In the sixth question, the score corresponds to the score of time, showing the expected time spent on learning, while in the seventh question, the score corresponds to the score of interaction, showing learners' discussion with peers and teachers. Finally, the score in the fifth question corresponds to that of adjustment, showing whether or not learners can reach the scores set by themselves, and the score in the eighth question can be used to adjust the score in the adjustment item based on the score in the six items.

The blue area in the radar chart, as presented in Figure 7, shows the learning records of the students, including knowledge enquiry, task design, reading, discussion, sharing, and problem solving. Researchers and five teachers agreed to distribute different time constraints to the tasks and teaching procedures, and give scores based on the six items mentioned above. The calculation of scores is described below. The maximum score for these items is 100 . 


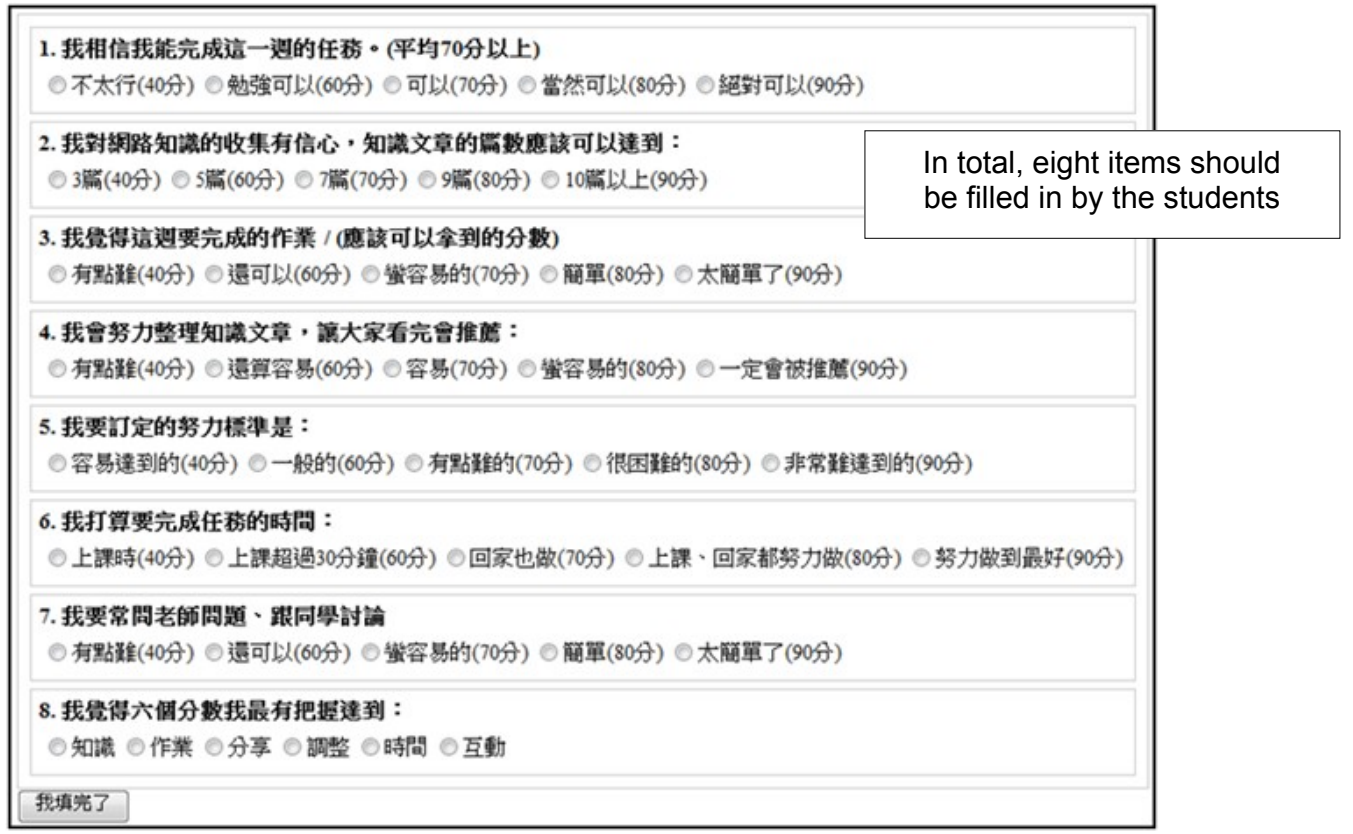

\section{Translation for Figure 6}

1. I believe that I can complete the assignments of this week (with the average more than 70 points). ODisagree (40 points) OSomewhat agree (60 points) OModerately agree (70 points) OAgree (80 points) OStrongly agree (90 points)

2. I am confident that I can find articles on different types of knowledge on the Internet. O3 articles (40 points) $\bigcirc 5$ articles ( 60 points) $\bigcirc 7$ articles (70 points) 09 articles ( 80 points) OMore than 10 articles (90 points)

3. I think that I can complete the assignments for this week (or indicate the score that you deserve). OA little difficult (40 points) OSomewhat easy (60 points) OModerately easy (70 points) OEasy ( 80 points) OVery easy (90 points)

4. I am working hard to find the articles on the internet. The articles would be recommended by my classmates after they read it.

OUnlikely (40 points) OLow possibility (60 points) OSomewhat possible (70 points) OLikely (80 points) OVery likely (90 points)

5. I make the level of difficulty or easiness for the goal with the following conditions:

OEasy to achieve (40 points) ONeither easy nor difficult (60 points) OSomewhat difficult to achieve (70 points) ODifficult to achieve (80 points) OVery difficult to achieve (90 points)

6. I intend to complete the assignments within the following period of time: ODuring the class (40 points) $\mathrm{O} 30$ minutes after the class begins (60 points) $\mathrm{OHome} \mathrm{(70} \mathrm{points)} \mathrm{OHome}$ and during the class ( 80 points) $\bigcirc$ Try my best (90 points)

7. I always ask my teacher questions and discuss problems with classmates.

OA little difficult (40 points) OSomewhat easy (60 points) OModerately easy (70 points) OEasy (80 points) OVery easy (90 points)

8. I think that I can achieve one of the following scores with the highest score. OKnowledge OAssignment OSharing OAdjustment OTime OInteraction

Figure 6: Learning goal setting function 


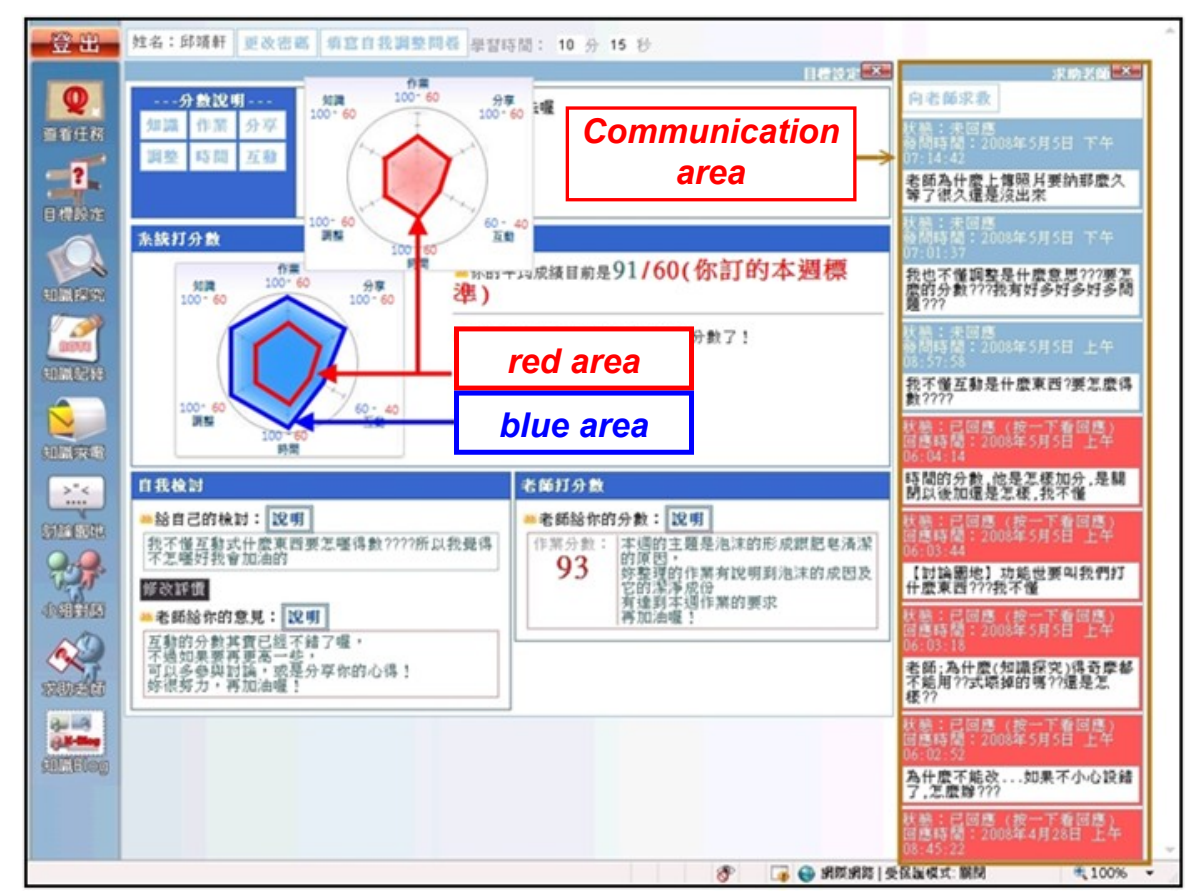

Figure 7: Learning goal and learning status diagram

1. Knowledge - In each task, learners need to collect, organise, and integrate information based on the time constraint each week. In this system, students can get 10 points in the knowledge item when they are able to accomplish each personal knowledge article based on the enquiry. They can get an extra 3 points for editing or revising each article after 5 minutes: one point for 10 times of being read for more than 1 minute and 2 points for articles being recommended by other peers.

2. Assignment - In teaching, teachers should ask learners to accomplish task enquiry, information organisation, question, discussion, and assignment completeness. Proper scores are given for each manipulation by students: 5 points for using the knowledge enquiry function to search for more than 3 minutes, and 2 points for asking teachers about the purpose of tasks in the process.

3. Sharing - Students can get 5 points for articles being recommended by others, 2 points for accomplishing each article, 1 point for being read for more than 1 minute, 3 points for giving feedback in the discussion board, and 1 point for getting responses on the same article.

4. Time - Students can get 60 points for using the system for more than 30 minutes in total, and 1.5 points for each minute beyond 30 minutes.

5. Interaction - Students can get 10 points for giving feedback in the discussion area assigned by teachers: 1 point for responding peers' articles, 2 points for recommending peers' articles which are valuable and 2 points for asking teachers for help. 
6. Adjustment - Students can get 15 points for reaching their expected scores for each item (when the blue part is displayed on top of the red part in Figure 7). The students will get an extra 10\% for reaching the expected scores in the eighth question of the goal setting sheet. Extra points are given by teachers when students ask questions about adjustment.

The number under the six items in Figure 7 is the real score (blue area, 91) - expected scores (red area, 60). Students can observe their learning situations based on this radar chart. Teachers and students can communicate directly through this system. Students can ask about goal setting and teachers can facilitate learners' entrance to the selfregulated learning cycle (Figure 7).

Strategy implementation and monitoring

In the radar chart (as stated in Figure 7), learners can organise information with graphics easily, evaluate their learning and expected scores, as well as monitor their progress. By using the blog, as shown in Figure 8, students can save the information obtained. Communication between teachers and students can solve students' doubts and remind them of information necessary for improving the integrity of their tasks.

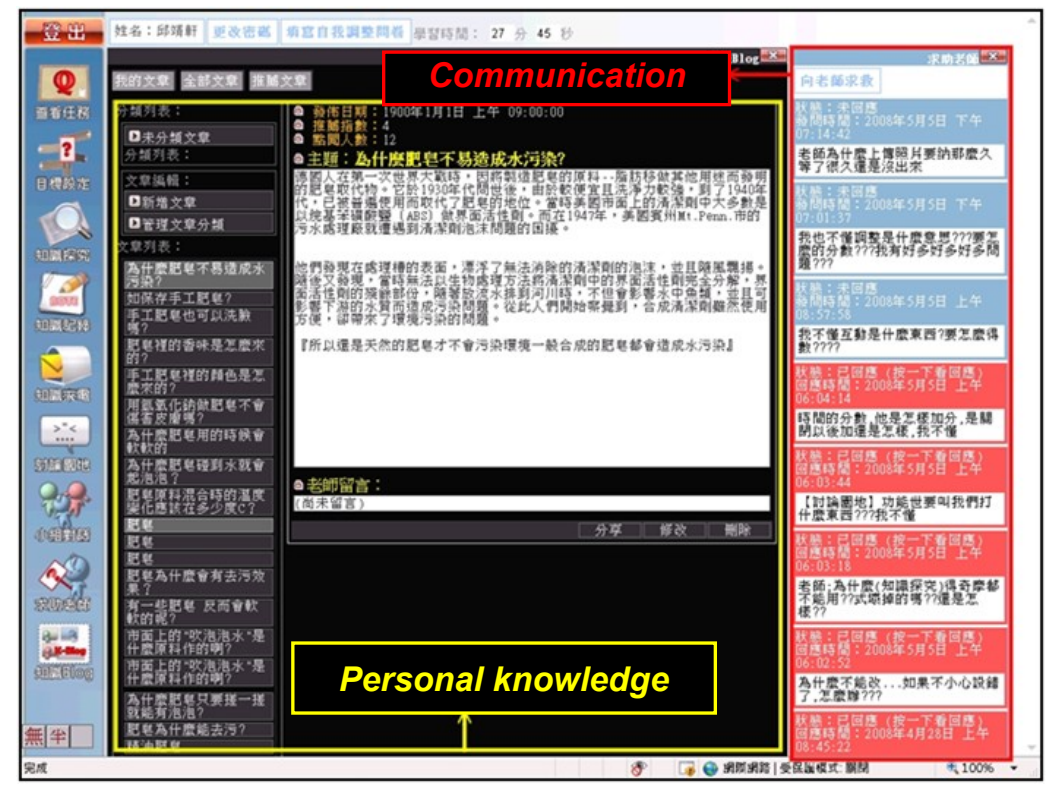

Figure 8: Personal knowledge record and communication module

Students can evaluate their progress by sharing their ideas and discussion with peers, as illustrated in Figure 9. In this process, the immediate communication function provides further information about knowledge websites, research method adjustment, and so on.

Strategy outcome monitoring

Teachers ask students evaluate their own progress, including their ideas about the process and strategy adjustment in the self-regulated learning cycle. Feedback is given by teachers after class, which serves as the reference for the next cycle. 


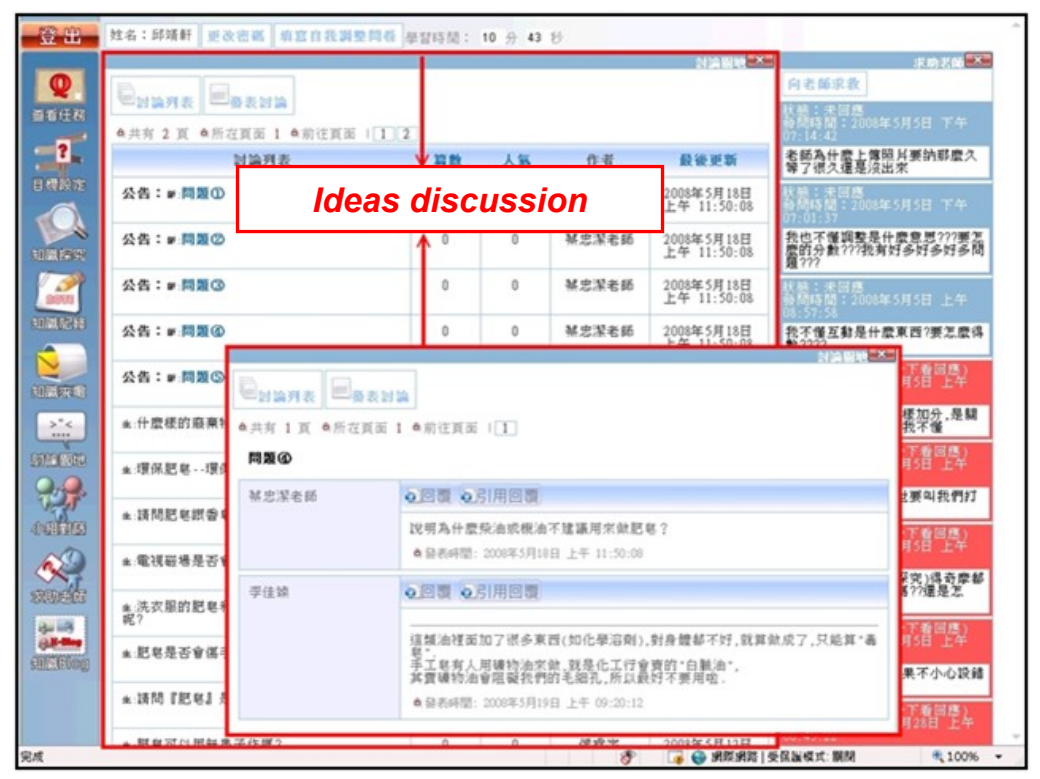

Figure 9: Sharing ideas and discussion

\section{Methods}

The study used both qualitative and quantitative approaches to answer the research questions. We used a quasi-experiment to study the effect in WebQuest learning, and sequential analysis to calculate students' particular interaction patterns (Bakeman \& Gottman, 1997; Gottman \& Roy, 1990). In addition, we also deduced and compared these patterns. This study was a five-week experiment, in which the independent variables were the WebQuest learning with as well as the WebQuest learning without self-regulated learning assisted functions, and self-regulated levels of the students, while the dependent variables were their learning effect. The study aimed to investigate the learning effect of students with high and low self-regulated levels. We also looked into differences in their self-regulated behaviour through their learning records.

\section{Subjects}

The participants in this study were sixth graders at an elementary school in Taipei County, including 193 students in six classes, with average 12 years. Three classes were assigned as the experimental group while the other three classes were regarded as the control group. The experimental group used WebQuest with self-regulated learning assisted functions for learning, and the control group used the traditional WebQuest system for learning. Both groups received a pre-test, and learning activities for five weeks, one hour per week.

\section{Procedure}

The experiment was administered in late April to May 2009 for five weeks. We designed the curriculum by following the competency indicators in Nature and Science Technology for the sixth grade. In the beginning of the experiment, both groups were 
asked to take the Environmental protection soap curriculum achievement test as the pretest. After the pre-test, the experimental group used WebQuest learning with selfregulated learning assisted functions and the control group used traditional WebQuest learning, which both lasted for five weeks. Environmental protection issues were covered in the curriculum, and the weekly learning activities are shown in Table 1.

Table 1: The weekly teaching plan

\begin{tabular}{|c|c|c|}
\hline $\begin{array}{l}\text { Teaching } \\
\text { activity }\end{array}$ & Teaching flow & $\begin{array}{l}\text { Attention } \\
\text { item }\end{array}$ \\
\hline $\begin{array}{l}\text { Problem } \\
\text { description }\end{array}$ & $\begin{array}{l}\text { 1. The teacher tells the students the weekly problem. } \\
\text { 2. The teacher leads each student to log into the inquiry } \\
\text { task website. }\end{array}$ & $\begin{array}{l}\text { 1. Make sure that the } \\
\text { students know the } \\
\text { problem and log into } \\
\text { the website. }\end{array}$ \\
\hline $\begin{array}{l}\text { Inquiry task } \\
\text { and } \\
\text { requirement } \\
\text { description }\end{array}$ & 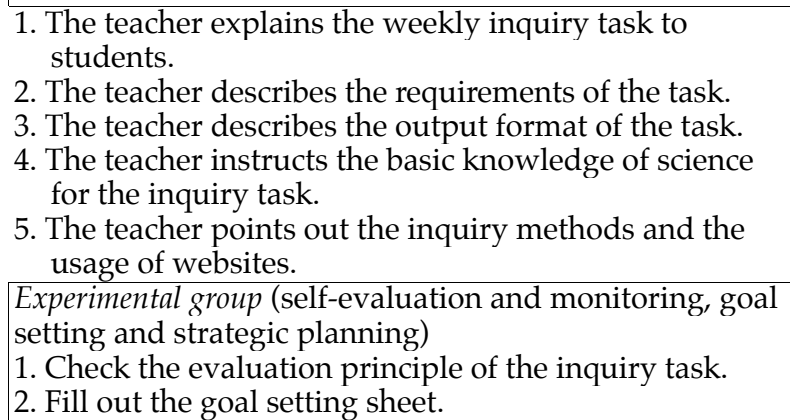 & $\begin{array}{l}\text { 1. Provides the search } \\
\text { techniques. } \\
\text { 2. Checks the } \\
\text { operational status of } \\
\text { students' computers. }\end{array}$ \\
\hline $\begin{array}{l}\text { Starting the } \\
\text { inquiry task } \\
\text { and } \\
\text { completing the } \\
\text { assignment }\end{array}$ & $\begin{array}{l}\text { 1. Students start the inquiry task. } \\
\text { 2. Students search the contents of websites to complete } \\
\text { the task. } \\
\text { 3. Students can search related websites. } \\
\text { 4. Students complete the assignment. } \\
\text { Experimental group (strategy implementation and } \\
\text { monitoring) } \\
\text { 1. Monitor the score of the goal and the current score. } \\
\text { 2. Use keywords to search in the WebQuest system. } \\
\text { 3. Edit the available information to complete the task. }\end{array}$ & $\begin{array}{l}\text { 1. Monitors the } \\
\text { learning status of the } \\
\text { students. } \\
\text { 2. Monitors the website } \\
\text { operation status of } \\
\text { the students. }\end{array}$ \\
\hline $\begin{array}{l}\text { Problem } \\
\text { discussion and } \\
\text { sharing } \\
\text { learning } \\
\text { experiences }\end{array}$ & $\begin{array}{l}\text { 1. The students provide feedback to the teacher's } \\
\text { questions. } \\
\text { 2. The teacher discusses the status of the assignment. } \\
\text { 3. The students share the learning experiences. } \\
\begin{array}{l}\text { Experimental group (strategy implementation and } \\
\text { monitoring) } \\
\text { 1. Discuss the questions with the teacher }\end{array}\end{array}$ & $\begin{array}{l}\text { 1. Checks the status of } \\
\text { the assignment. } \\
\text { 2. Provides search } \\
\text { methods. }\end{array}$ \\
\hline $\begin{array}{l}\text { Modifying the } \\
\text { contents of the } \\
\text { assignment }\end{array}$ & $\begin{array}{l}\text { Experimental group (strategic outcome monitoring) } \\
\text { 1. Provide feedback of the learning experiences. } \\
\text { 2. Give the self-review of the task. }\end{array}$ & $\begin{array}{l}\text { 1. Monitors the } \\
\text { assignment status of } \\
\text { the students. } \\
\text { 2. Describes the upload } \\
\text { operation of the } \\
\text { assignment. }\end{array}$ \\
\hline $\begin{array}{l}\text { Uploading the } \\
\text { assignment } \\
\text { and receiving } \\
\text { explanations } \\
\text { from the } \\
\text { teacher }\end{array}$ & 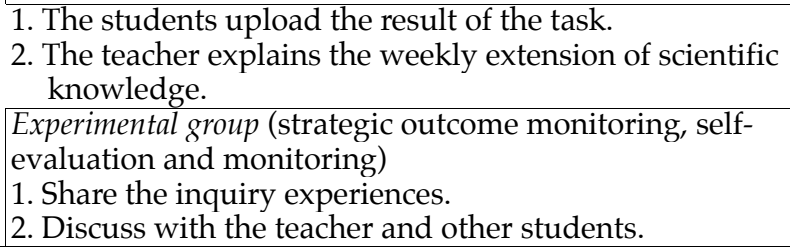 & $\begin{array}{l}\text { 1. Checks the upload } \\
\text { status of the } \\
\text { assignment. } \\
\text { 2. Explains the } \\
\text { knowledge of } \\
\text { science. }\end{array}$ \\
\hline
\end{tabular}


Self-regulated learning cycle activities were added in the experimental group in addition to other equivalent factors. During the learning activities, the system and the researcher recorded each student's learning situation for both groups. When the treatment ended, both groups took the Environmental protection soap curriculum achievement test as the post-test. Regarding the data analysis, the study adopted oneway ANCOVA for independent samples to discuss the effects of different teaching methods on students' learning results. The two teaching methods were the independent variables, the post-test scores were the dependent variables, and the scores of pre-test were the covariance. The $\alpha$-level was set at $5 \%$. Secondly, the study used the score of achievement test as the covariate, teaching methods and selfregulated levels as the independent variables, and the score of post-test as the dependent variable. MANOVA was used to examine the experimental group and the control group in terms of learners with high and low self-regulated level $(\alpha=.05)$. Finally, by using sequential analysis, we observed both groups in their learning to calculate the results and give explanations based on their learning scores and records.

\section{Instruments}

As indicated in the 'Procedure' section above, the Environmental protection soap curriculum achievement test and children's self-regulated scale were used as instruments in this study.

\section{Environmental protection soap curriculum achievement test}

Environmental protection soap is the curriculum topic in this study for the sixth graders' WebQuest learning. Based on the curriculum design, we constructed the test by following the competence indicators in Nature and Science Technology subject for the sixth grade. It was administered two times, firstly as a pre-test and secondly as a post-test, in order to investigate the potential effects of different teaching methods on the participants. The number of test items and the difficulty level were the same but what is covered in the tests was different.

Three teachers of Nature and Science Technology subject designed the test according to the teachers' manual and competency indicators in the Nature and Science Technology subject for the sixth graders. The total score for the test is 100 . Drafts of the test were reviewed by three professors from related fields according to the propositional knowledge statements table and two-way specification table, to check the appropriateness of the test and to construct expert validity. Samples for the pilot test were 231, and 216 were valid. The results of data analysis, $\mathrm{Kr}=0.82$, suggested that high reliability. $\mathrm{Kr}$ was considered highly reliable when $\mathrm{Kr}>0.7$ (Wortzel, 1979).

\section{Children's self-regulated scale}

The study modified the self-regulated scale developed by Zimmerman and Kitsantas (2002) to investigate students' self-regulated level. The scale, including 96 items in total, involves motivation, behaviour controlling, cognitive strategy, and metacognition. Samples for the pilot test were 231, of which 214 were valid. This questionnaire used a 5-point Likert scale, and the Cronbach $\alpha$ for the scale was .98; .91 to .95 for subcategories. It showed that the scale was consistent (the stable reliability score was .85, which revealed that it was highly stable in contents). This scale enabled teachers to ascertain differences in learners' self-regulated levels in order to provide necessary scaffolding. To distinguish accurately between the high and low selfregulators, the $27 \%$ rule proposed by Cureton (1957) was used as the classification 
standard. Thus, based on the score of the Children's self-regulated scale, the upper $27 \%$ were regarded as high self-regulators and the lower $27 \%$ were regarded as low selfregulators.

\section{Results}

\section{Descriptive statistics}

This study developed a WebQuest learning system based on the self-regulated learning cycle model. The teaching material was from the unit of environmental protection in Nature and Science Technology subject. Both the experimental and control groups participated in the five-week experiment. Before the experiment, we gave each group the Environmental protection soap curriculum achievement tests, which were used as a pre-test. After the pre-test, the experimental group used WebQuest learning with selfregulated learning assisted functions, and the control group used the traditional WebQuest learning system

This study chose six classes of sixth grade from an elementary school in Taipei County, and assigned three classes as the control group and the other three classes as the experimental group, with 193 participants in total. After eliminating the missing samples, the sample number was 159 . The study used children's self-regulated scale as a pre-test to determine learners whose scores fell on the first $27 \%$ as high selfregulators, and learners whose scores fell on the last $27 \%$ as low self-regulators. Detailed information is provided in Table 2.

Table 2: Descriptive statistics for the study

\begin{tabular}{|c|c|c|c|c|c|c|c|}
\hline \multirow{2}{*}{ Group } & \multirow{2}{*}{$\mathrm{N}$} & \multicolumn{2}{c|}{ Pre-test } & \multicolumn{2}{c|}{ Post-test } & \multicolumn{2}{c|}{ Adjusted post-test } \\
\cline { 3 - 8 } & & Mean & SD & Mean & SD & Mean & SD \\
\hline Experimental group & 78 & 61.38 & 9.78 & 72.27 & 0.77 & 72.12 & 0.78 \\
\hline high self-regulated level & 23 & 62.43 & 10.26 & 75.77 & 1.28 & 75.55 & 1.16 \\
\hline low self-regulated level & 22 & 58.59 & 12.99 & 71.25 & 1.39 & 71.07 & 1.42 \\
\hline Control group & 81 & 61.17 & 11.49 & 64.53 & 0.76 & 64.59 & 0.78 \\
\hline high self-regulated level & 20 & 64.15 & 6.69 & 69.82 & 1.38 & 69.95 & 1.33 \\
\hline low self-regulated level & 21 & 60.33 & 11.49 & 61.07 & 1.42 & 61.14 & 1.48 \\
\hline
\end{tabular}

\section{Analysis of learning effects of different systems}

In the beginning it was necessary to check the equality of variance, which confirmed the homogeneity of variance for the two groups. The homogeneity within regression coefficient was not significant $(F=1.70, p>.05)$, which accorded with requirements for ANCOVA. In Table 3, we used the pre-test scores as the covariate, and the post-test scores as the dependent variable. ANCOVA was used to test the significant difference between the two groups $(\alpha=.05)$. The results showed that there was a significant difference between different teaching methods and achievement $(F=50.52, p<.05)$. Thus, it was important to know which teaching method was better. After eliminating the effect of the pre-test scores, the study still found the experimental group obviously outperformed the control group, which was shown in the adjusted means of the posttest (Table 2). The adjusted mean of the post-test of the experimental group and that of the control group were 72.12 and 64.59 respectively. This statistically significant difference indicated that the WebQuest system with self-regulated assisted functions proposed by the study was effective in improving the inquiry learning. In addition, the 
effect size indicator, $\eta^{2}$, of the analysis was .245. It proved that teaching methods and learning retention did have a strong association, with the effect size indicator being greater than .14 (Cohen, 1988). The result revealed that the WebQuest system with selfregulated assisted functions could help the learners in the experimental group improve their learning outcomes.

Table 3: One-way ANCOVA of the tests

\begin{tabular}{|l|c|c|c|c|c|c|}
\hline \multicolumn{1}{|c|}{ Sources of variation } & $S S$ & $d f$ & $M S$ & $F$ & $p$ & $\eta^{2}$ \\
\hline Between groups (Treatment) & 2368.404 & 1 & 2368.404 & $50.52^{* *}$ & $<.001$ & .245 \\
\hline Within groups (Error) & 7312.833 & 156 & 46.877 & & & \\
\hline${ }^{* *} p<.01$
\end{tabular}

\section{Analysis of learning effect of high and low self-regulators}

To understand the differences between the high and low self-regulated level learners who practiced WebQuest learning with self-regulated learning assisted system, and to investigate the effectiveness of the system, this study set self-regulated levels and teaching methods as the independent variables, set the Environmental protection soap knowledge pre-test as the covariate, and set the Environmental protection soap assignment post-test as the dependent variable, with the use of MANOVA. The homogeneity within regression coefficient was not significant $(F=0.34, p=.797>.05)$, which accorded with a requirement for MANOVA. Table 4 shows that there were no significant differences between the two variables $(F=2.427, p>.05)$, and no significant differences in terms of self-regulated level $(F=12.435, p<.05)$. Thus, we observed directly the influence of the teaching methods on the high and low self-regulators.

Table 4: Summary of MANOVA

\begin{tabular}{|l|c|c|c|c|c|c|}
\hline \multicolumn{1}{|c|}{ Sources of variation } & $S S$ & $d f$ & $M S$ & $F$ & $p$ & $\eta^{2}$ \\
\hline Group & 1379.477 & 1 & 1379.477 & $34.948^{* *}$ & $<.001$ & .301 \\
\hline Self-regulated level & 490.835 & 1 & 490.835 & $12.435^{* *}$ & .001 & .133 \\
\hline Group ${ }^{*}$ Self-regulated level & 95.817 & 1 & 95.817 & 2.427 & .123 & .029 \\
\hline Error & 3197.253 & 81 & 39.472 & & & \\
${ }^{* *} p<.01$
\end{tabular}

In the high self-regulated level group, 23 participants were in the experimental group and 20 participants in the control group. The significant results are shown in Table 5 $(F=9.96 ; p<.05)$. Table 2 shows that the high self-regulated learners of the experimental group who practised WebQuest learning with self-regulated learning assisted functions had higher scores than those of the control group, which indicated better learning effect. Table 2 also shows that the effect size indicator $\eta^{2}$ of the analysis was .199 , which showed that the learning effect of the high self-regulated learners in the experimental group could be improved by the proposed system.

Table 5: ANCOVA for high self-regulated level groups

\begin{tabular}{|l|c|c|c|c|c|c|}
\hline \multicolumn{1}{|c|}{ Sources of variation } & SS & $d f$ & $M S$ & $F$ & $p$ & $\eta^{2}$ \\
\hline Between groups (Treatment) & 375.528 & 1 & 375.528 & $9.96^{* *}$ & .003 & .199 \\
\hline Within groups (Error) & 1507.931 & 40 & 37.698 & & & \\
\hline${ }^{* *} p<.01$
\end{tabular}

In the low self-regulated level group, 22 participants were in the experimental group and 21 participants were in the control group. The significant results are shown in 
Table $6(F=26.021 ; p<.01)$. As shown in Table 2, the low self-regulated learners of the experimental group who practiced WebQuest learning with self-regulated learning assisted functions had higher scores than those of the control group after adjustment, which showed better learning outcome. Since the effect size indicator $\eta^{2}$ of the analysis was .394, we inferred that the low self-regulated learners in the experimental group were assisted by the proposed system. Thus, they were able to attain better learning outcomes.

Table 6: ANCOVA for low self-regulated level groups

\begin{tabular}{|l|c|c|c|c|c|c|}
\hline \multicolumn{1}{|c|}{ Sources of variation } & $S S$ & $d f$ & $M S$ & $F$ & $p$ & $\eta^{2}$ \\
\hline Between groups (Treament) & 1098.925 & 1 & 1098.925 & $26.02^{* *}$ & $<.001$ & .394 \\
\hline Within groups (Error) & 1689.314 & 40 & 42.233 & & & \\
\hline${ }^{* *} p<.01$
\end{tabular}

According to the results above, when eliminating the impact from the pre-test, the high self-regulators who practiced WebQuest learning with self-regulated learning assisted functions had higher scores in the post-test than those who used traditional WebQuest learning. Similarly, when eliminating the impact from the pre-test, the low selfregulators who practised WebQuest learning with self-regulated learning assisted functions had higher scores in the post-test than the low self-regulators who used traditional WebQuest learning.

Differences between the 23 high self-regulators and 22 low self-regulators in the experimental group in the post-test were observed. As shown in Table 7, there was no significant difference between them. Even though the high self-regulators had higher mean scores than the low self-regulators, there was no difference in the post-test.

Table 7: ANCOVA for high and low self-regulated levels in the experimental group

\begin{tabular}{|l|c|c|c|c|c|c|}
\hline \multicolumn{1}{|c|}{ Sources of variation } & $S S$ & $d f$ & $M S$ & $F$ & $p$ & $\eta^{2}$ \\
\hline Between groups (self-regulated level) & 73.625 & 1 & 73.625 & 1.55 & .220 & .036 \\
\hline Within groups (Error) & 1990.517 & 42 & 47.393 & & & \\
\hline
\end{tabular}

Differences between the 20 high self-regulators and 21 low self-regulators in the control group in the post-test were observed. As shown in Table 8, there was a significant difference between the two. The high self-regulators had higher mean scores than the low self-regulators, as shown in Table 2. It is important to note that the effect size indicator $\eta^{2}$ of the analysis reached .300, the factor of self-regulated level influenced highly learning outcomes for the control group.

Table 8: ANCOVA for high and low self-regulated levels in the control group

\begin{tabular}{|l|c|c|c|c|c|c|}
\hline \multicolumn{1}{|c|}{ Sources of variation } & $S S$ & $d f$ & $M S$ & $F$ & $p$ & $\eta^{2}$ \\
\hline Between groups (self-regulated level) & 508.392 & 1 & 508.392 & $16.27^{* *}$ & $<.001$ & .300 \\
\hline Within groups (Error) & 1187.217 & 38 & 31.243 & & & \\
\hline${ }^{* *} p<.01$ &
\end{tabular}

In these results, no significant differences between the high self-regulators and the low self-regulators in the experimental group were found in the post-test. In the control group, the mean score of the high self-regulators was higher than that of the low selfregulators in the post-test, which reached a significant level. The post-test result showed that the scores in both high and low self-regulated levels of the experimental group were higher than those of the control group. 
Differences in the learning effect between the 20 high self-regulators in the control group and 22 low self-regulators in the experimental group were observed. As shown in Table 9, the adjusted scores in the post-test of the low self-regulators in the experimental group were higher than those of the high self-regulators in the control group, but there was no significant difference.

Table 9: ANCOVA for low self-regulators in the experimental group and high self-regulators in the control group

\begin{tabular}{|l|c|c|c|c|c|c|}
\hline \multicolumn{1}{|c|}{ Sources of variation } & $S S$ & $d f$ & $M S$ & $F$ & $p$ & $\eta^{2}$ \\
\hline Between groups (self-regulated level) & 92.754 & 1 & 92.754 & 3.03 & .089 & .072 \\
\hline Within groups (Error) & 1192.727 & 39 & 30.583 & & & \\
\hline
\end{tabular}

The study aimed to investigate whether WebQuest learning with self-regulated learning assisted functions can improve the learning effect. According to the analysis in this section, with the exclusion of impact from the pre-test, learners undertaking WebQuest learning with self-regulated learning assisted functions outperformed learners undertaking traditional WebQuest learning, in terms of both high and low self-regulated levels. Thus, we concluded that WebQuest learning with self-regulated learning assisted functions can improve the learning effect. Figure 10 summarises the data analysis for the study.

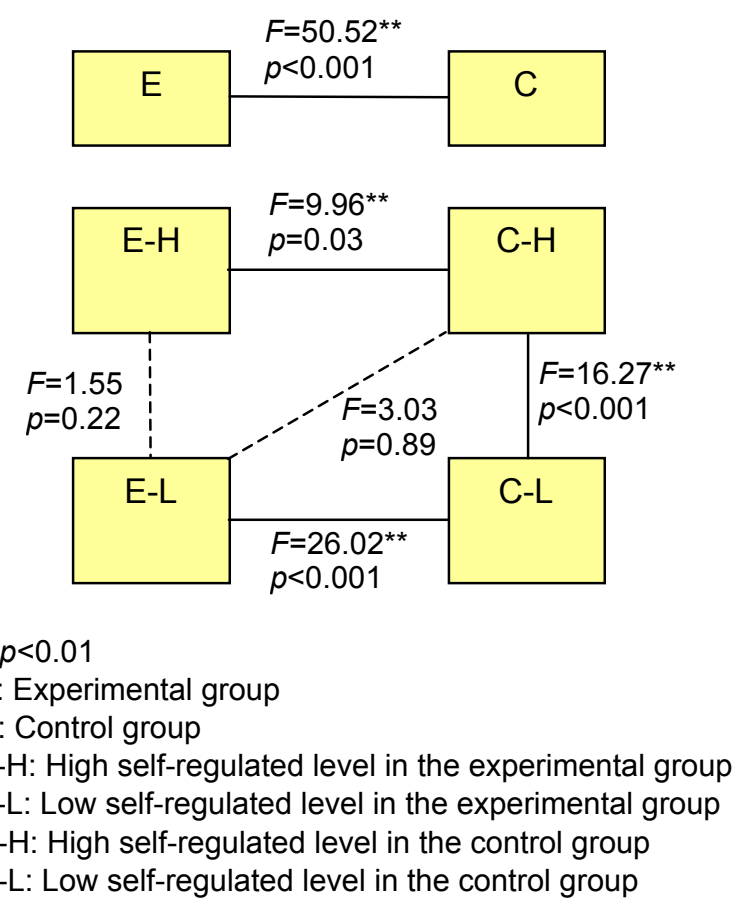

Figure 10: Summary of data analysis

\section{Analysis of self-regulated behaviour}

During the learning processes, all of the actions of the participants were recorded by the system. Based on the conclusion in the previous section, the participants in the 
experimental group made better progress in terms of their learning outcomes. We further examined the reasons why this system can improve the learning effect by looking into participants' self-regulated behaviour and the principles and frequency of the system to support the conclusion made in the previous section. Their actions were defined as six behaviour indices in WebQuest learning, based on their learning records, which are shown below:

1. Task check (T): Students check the tasks and fill out the goal setting sheet.

2. Editing (E): After searching for related information for the task, students edit the information on their own or with teachers' help.

3. Keyword search (K): Students search for keywords or revise keywords after searching, or revising searching after finding results.

4. Question discussion (Q): Students discuss questions with teachers in WebQuest learning.

5. Scores check (S): Students check their task scores.

6. Others $(\mathrm{O})$ : Records and behaviour which are not defined by the above indexes. For example, behaviour that is not related to WebQuest learning.

Table 10 is the comparison table of the six behavioural indices for sequential analysis and the self-regulated learning processes proposed by Zimmerman et al. (1996). The learning behaviours of all participants, including the experimental and control groups, were coded according to the learning behavioural indices stated above. The coder coded the behaviours chronologically, based on the behavioural indices in Table 10. For example, after task check (T), a student edits the information for the task (E), which is coded TE. After all the participants' behaviour was coded, there were 63 pairs of coding sequence and 5,418 codes. Thirty-eight pairs of sequences (occupying about $60 \%$ of the sequence) picked by the researcher were coded by the second researcher. The inter-rater reliability, with kappa $=.71$, was substantial.

The sequential analysis was then applied to the coded data for the purpose of testing the relevance of the sequence between the participants' behaviour (Bakeman, \& Gottman, 1997). The study, after analysing the data, summarised several frequency transition tables and adjusted residuals tables; finally, frequency bar charts and transition diagrams were drawn. The study used DAT v1.7 in the sequential analysis to visualise learner behaviour in WebQuest learning according to the encoded behaviour by producing behavioural transition diagrams, which display what happened in terms of self-regulated behaviour.

Table 10: The summary of self-regulated processes and behaviour definitions

\begin{tabular}{|l|l|}
\hline \multicolumn{1}{|c|}{ Self-regulated process } & \multicolumn{1}{c|}{ Behaviour index } \\
\hline Self-evaluation and monitoring & Task check (T), Scores check (S) \\
\hline Goal setting and strategic planning & Task check (T) \\
\hline $\begin{array}{l}\text { Strategic implementation and } \\
\text { monitoring }\end{array}$ & $\begin{array}{l}\text { Editing (E), Keyword search (K), Scores check (S), } \\
\text { Question discussion (Q) }\end{array}$ \\
\hline Strategic outcome monitoring & Scores check (S), Question discussion (Q) \\
\hline
\end{tabular}

Analysis of high self-regulators in the experimental group

To understand the behaviour patterns of the high self-regulators in WebQuest learning with the system, the study assigned numbers to all behaviours of the learners in WebQuest learning, and produced a behavioural transition diagram, shown in Figure 11. In Figure 11, words in the diagram represent the indices defined by the study, and 
the arrow leads to the behaviour after a certain behaviour has been done. Numbers on the arrows show the percentage of occurrence, indicating the frequency of the certain behaviour occurrence followed by the next (Bakeman \& Gottman, 1997). The study, based on the theory of self-regulated learning cycle and six indexes defined in the study, categorised six self-regulated behaviours.

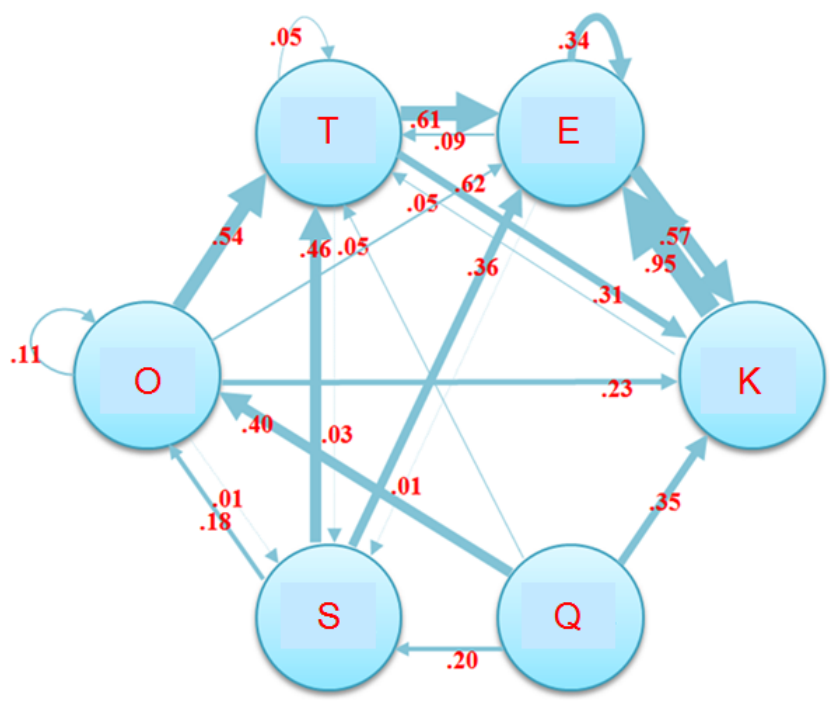

Figure 11: The transition diagram for high self-regulators in the experimental group

The self-regulated behaviour for high self-regulators in the experimental group is:

1. Self-evaluation and monitoring - By checking their scores for the task, students reevaluated the task, its goal, and regulations before searching as well as editing their assignments. According to Figure 11, after checking the scores, high self-regulators in the experimental group re-evaluated their tasks $(S \rightarrow T, .46)$ and edited their assignments after checking $(\mathrm{T} \rightarrow \mathrm{E}, .61)$. It was obvious that the high self-regulators in the experimental group could evaluate and monitor by themselves in the learning processes.

2. Goal setting and strategic planning - Students understood the goal after checking the task, and set the way of searching to look for the keywords and to edit information. If needed, they revised keywords, searching ways and contents of assignments based on the information they found. According to Figure 11, in terms of the high self-regulators in the experimental group, the frequencies of their move from task check to assignment editing $(\mathrm{T} \rightarrow \mathrm{E}, .61)$ and to the cycle of task check, search, edit $(\mathrm{T} \rightarrow \mathrm{E}, .61, \mathrm{~T} \rightarrow \mathrm{K}, .31, \mathrm{~K} \rightarrow \mathrm{E}, .95, \mathrm{E} \rightarrow \mathrm{K}, .57)$ as well as the move from keyword searching and editing $(K \rightarrow E, .95, E \rightarrow K, .57)$ were high. This showed the construction of metacognition by learners, as seen in their revision in the learning process.

3. Strategic implementation and monitoring - The students checked their scores and further re-evaluated the task, searched, and edited, which showed that they monitored their learning and concentration on the task. According to Figure 11, in terms of the high self-regulators in the experimental group, the frequency of their 
move from task check to keyword searching, and to assignment editing was high. Most of the students' behaviour focused on editing. Though the frequency of other behaviour was high after discussion with teachers, the move from other behaviour to editing was also occurred with high frequency, which indicated students' concentration on WebQuest learning.

4. Strategic outcome and monitoring - After discussion or score checking, when learners went back to re-evaluate their tasks, it showed that they were willing to review and revise the task. According to Figure 11, in terms of the move to re-evaluate the task, the frequency for high self-regulators in the experimental group was .46 $(S \rightarrow T)$. After the discussion, it was not obvious that students went back to the task. The results showed that the high self-regulators in the experimental group did retrospect, but not in an obvious way.

Based on the above observations, self-regulated behaviour occurred in the abovementioned items for high self-regulators in the experimental group, especially in strategic implementation and monitoring.

Analysis of low self-regulators in the experimental group

Using the same method, the study coded all behaviour of the low self-regulators in the experimental group, and produced behavioural transition diagrams, as shown in Figure 12.

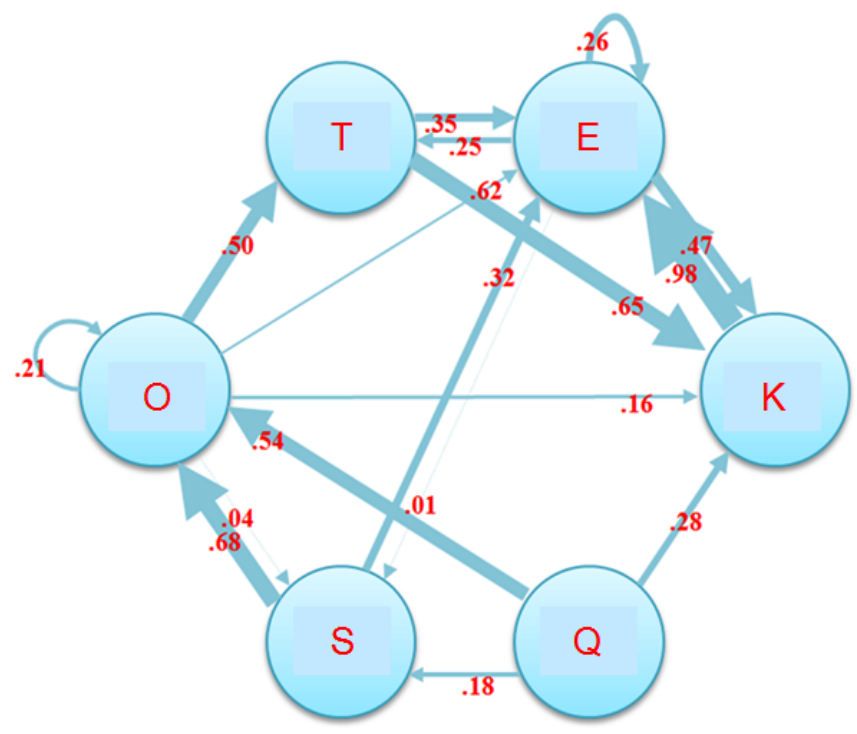

Figure 12: Transition diagram for low self-regulators in the experimental group

Details in Figure 12 are stated in the following:

1. Self-evaluation and monitoring - Based on Figure 12, low self-regulators of the experimental group did not re-evaluate the task after checking scores $(S \rightarrow T)$, which indicated that self-evaluation and monitoring did not occur in the low selfregulators of the experimental group. 
2. Goal setting and strategic planning - After finishing a task, the most frequent behaviour by the low self-regulators in the experimental group was to go into the other state $(\mathrm{O})$. However, many learners could move to goal setting and strategic planning step $(\mathrm{T})$ by the assisting system in the end $(\mathrm{O} \rightarrow \mathrm{T}, .5)$.

3. Strategic implementation and monitoring - The frequency was high in the low selfregulators' move from task check to keyword searching, assignment editing $(\mathrm{K} \rightarrow \mathrm{E} \rightarrow \mathrm{K}, .98, .47)$; and to editing after score checking, which showed learners' concentration on their assignments $(S \rightarrow E, .32)$. After score checking, learners tended to do other things $(S \rightarrow O, .68)$; however, the frequency of their move between reevaluation and task was high $(\mathrm{O} \rightarrow \mathrm{T}, .50)$, which showed that learners were practising strategic implementation and monitoring.

4. Strategic outcome and monitoring - After discussion and score checking, learners did not re-evaluate their task $(S \rightarrow T, Q \rightarrow T)$, which showed that there was no occurrence of monitoring and revision of strategy results.

Based on the observations above, although the low self-regulators of the experimental group tended to do other things, they were still willing to continue WebQuest learning, and the frequency of searching and editing was getting higher. Although the strategic outcome and monitoring behavior of the learners did not occur frequently, the system could promote self-regulated behaviour and learning by the low self-regulators in the experimental group.

Analysis of high self-regulators of the control group

During the learning processes, the study recorded all behaviour of the high selfregulators in the control group, and produced behavioural transition diagrams, as shown in Figure 13.

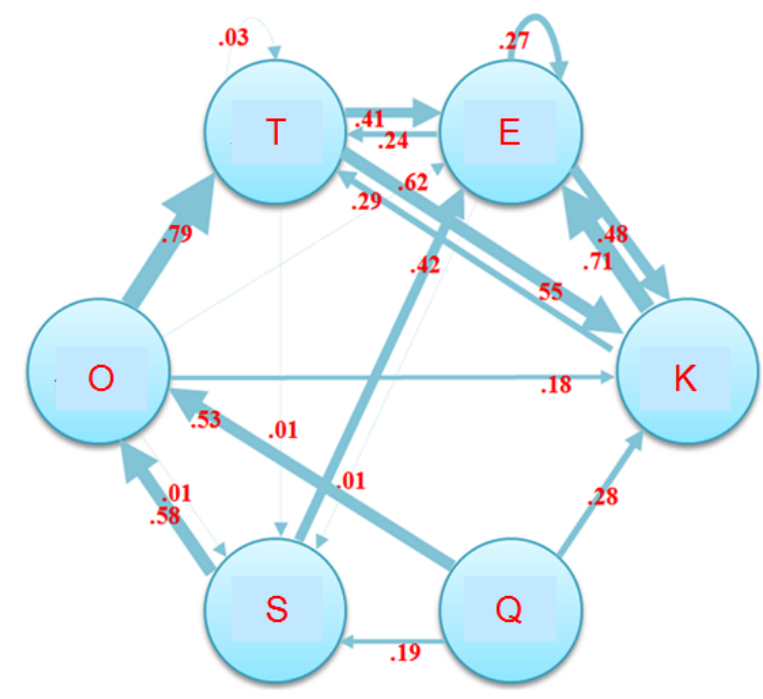

Figure 13: Transition diagram for high self-regulators in the control group

Details in Figure 13 are stated as follows. 
1. Self-evaluation and monitoring - Based on Figure 13, high self-regulators in the control group did not re-evaluate the task after checking their scores $(S \rightarrow T)$. Thus, selfevaluation and monitoring did not occur.

2. Goal setting and strategic planning - In terms of the high self-regulators in the control group, the frequency of their move from task check to keyword searching, and assignment editing was high $(\mathrm{K} \rightarrow \mathrm{E} \rightarrow \mathrm{K}, .71, .48$, respectively), which indicated that behaviour of goal setting and strategic planning was distinct.

3. Strategic implementation and monitoring - Though after checking scores, learners tended to do other things $(S \rightarrow O, .58)$, and the frequency of their move between reevaluation and task was high $(\mathrm{O} \rightarrow \mathrm{T}, .79)$, which showed that learners were practising strategic implementation and monitoring with their own self-regulated constraints and continuing learning.

4. Strategic outcome and monitoring - After discussion and scores check, learners did not re-evaluate their task, which indicated that there was no occurrence of selfregulated behaviour on monitoring and revision of strategic results.

Based on the observations above, although the high self-regulators of the control group did not show excellent self-regulated behaviour in the process, their concentration on tasks and re-evaluation was comparable to the high self-regulators of the experimental group, which showed that they had a good command of self-regulation and concentration.

Analysis of low self-regulators in the control group

The transition diagram of learning behaviour of low self-regulators in the control group is shown in Figure 14.

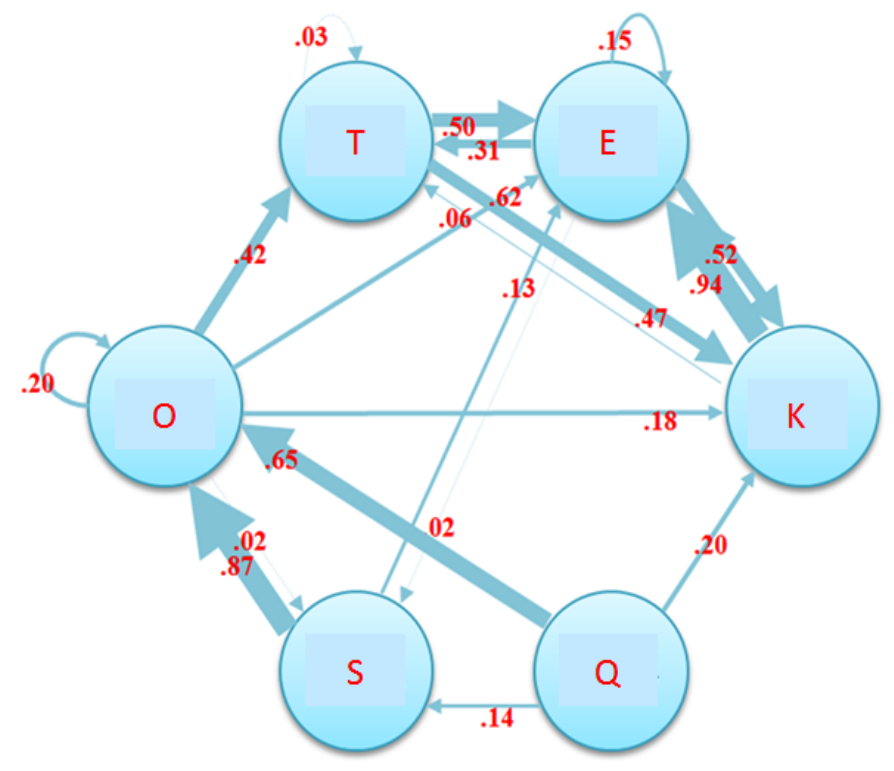

Figure 14: Transition diagram of low self-regulators in the control group 
The detailed descriptions for the diagram are stated in the following.

1. Self-evaluation and monitoring - Based on Figure 14, we noted that the low selfregulators in the control group did not re-evaluate the task after checking their scores $(S \rightarrow T)$. Thus, the learners did not have the self-regulated behaviour of selfevaluation and monitoring.

2. Goal setting and strategic planning - As we can see in Figure 14, the low selfregulators in the control group did not re-evaluate the task $(\mathrm{T})$, which indicated that there was no occurrence in goal setting and strategic planning.

3. Strategic implementation and monitoring - After task check (T), learners moved between knowledge searching and editing $(\mathrm{T} \rightarrow \mathrm{E}, .50)$ and between keyword searching and editing $(\mathrm{K} \rightarrow \mathrm{E} \rightarrow \mathrm{K}, .94, .52$, respectively), which indicated that learners were practising strategy implementation, monitoring and concentration in their learning process. Although the learners were low-regulated, the WebQuest system could lead the learners to complete the inquiry task.

4. Strategic outcome and monitoring - After discussion (Q), or scores check (S), learners tended to do other things $(\mathrm{Q} \rightarrow \mathrm{O}, .65, \mathrm{~S} \rightarrow \mathrm{O}, .87)$, and most of them failed to continue learning $(S \rightarrow E, .13)$, which showed that there was no self-regulated behaviour in this part.

Based on the observation above, the low self-regulators of the control group seldom showed self-regulated behaviour. However, in the open learning environment, they tended to do other things rather than learning, which resulted in low learning efficacy. Nevertheless, the WebQuest system could help the learners complete the task.

\section{Conclusion}

The study developed a WebQuest learning system with self-regulated learning assisted functions, based on the self-regulated learning cycle model. The results of the experiment showed the advantages of the system in learning and task accomplishment. Thus, with the help of self-regulated learning assisted functions, a new and more appropriate learning pattern is developed for elementary school students for WebQuest learning. The summary of data analysis is presented in Figure 10. The study indicated that the students in primary schools do not have good control of self-regulation in the Internet learning environment, and that they might lose in such an open learning environment. Thus, the further studies of ICT implementation in primary schools should provide some kind of self-regulated learning assisted functions to assist students' learning.

The study developed self-regulated learning assisted functions for WebQuest learning, which can help students evaluate goals, check scores, self-monitor, and adjust, based on the self-regulated learning cycle model. The comparison of the pre-test and post-test showed that the scores by learners using the proposed system were obviously higher than those attained by learners using the traditional WebQuest learning system, as shown in Table 2.

The results of the study showed that without the help of the system, there would be significant differences between high and low self-regulators in WebQuest learning. The 
low self-regulators were not able to easily reach the requirements of the tasks, as shown in Table 8 . However, there would be no change in the self-regulation level before and after the experiment as the system can assist low self-regulators in accomplishing the task, which was comparable to the high self-regulators, as shown in Table 7. Thus, the self-regulated learning assisted functions for WebQuest learning improved the effect of task-based learning for low self-regulators. In order to prevent the students from losing self-control, teachers who want to use WebQuest in their teaching should provide self-regulated learning assisted functions for guiding the learning process.

Comparing WebQuest learning with and without the self-regulated learning assisted functions, we found that the proposed system could promote the frequency of selfregulated learning behaviour, searching, and editing, as shown in Figures 11 and 12. It also helped the low self-regulators search and retrospect their scores, which increased the effect of WebQuest learning, as illustrated in Figure 12.

Limitations of the current study and recommendations for future studies are discussed as follows.

Firstly, the participants of the study were sixth grade students. At the beginning of the experiment, the students could not operate the system very fluently. In addition, the students were also not familiar with the self-regulated and inquiry processes. The study suggests that the teacher can give more time for students to practise using the system.

Second, the proposed system provides online communication and monitoring functions for the teacher to monitor and to assist students in a real time manner. In an open ended inquiry learning environment, the teacher must spend more time on helping students rather than focusing on traditional teaching methods.

Third, each course only has one hour. The students needed to complete the steps of task comprehension, inquiry process, integrated knowledge, and exercise uploading. The time was very tight for these students. We suggest that the teacher should try to simplify the learning tasks or to extend the learning time of each course. If the teacher can combine other teaching strategies to design WebQuest learning activities used by the students at home, we believe that the learning motivation of the students could be improved. When they have plenty of time to search for data and to reflect upon their learning status, the number of inquiry tasks could be increased.

Furthermore, the self-regulated learning assisted functions can be implemented in other learning systems to provide self-evaluating and monitoring mechanisms for students. For illustration, the digital game-based learning system is a good example which provides a self-regulated and immersion learning environment for students by combining the self-regulated learning assisted functions.

Finally, the study found that high-score students spent most of the time in task check and score check status. In addition, they were always in task check, keyword searching and editing states in order to complete the inquiry tasks. In future studies, the learning system could be implemented with suggestion functions, to offer proper learning paths for students. In this way, it can help the students enhance the learning effect. 


\section{Acknowledgment}

This research is supported by the "Aim for the Top University Plan" of the National

Taiwan Normal University, the Ministry of Education Taiwan and the National Science Council Taiwan under Grants 100-2631-S-003-001-, 98-2511-S-003-024-MY3.

\section{References}

Azevedo, R. \& Cromley, J. G. (2004). Does training on self-regulated learning facilitate students' learning with hypermedia? Journal of Educational Psychology, 96(3), 523-535. http: / / psycnet.apa.org/ doi/10.1037/0022-0663.96.3.523

Bakeman, R. \& Gottman, J. M. (1997). Observing interaction: An introduction to sequential analysis (2nd ed.). Cambridge University Press: Cambridge.

Belgiorno, F., Malandrino D., Manno, I., Palmieri, G. \& Scarano, V. (2009). Computer-supported WebQuest. Lecture Notes in Computer Science, 5794, 712-718. http: / / www.springerlink.com/ content/3601m5414w3j6x6t/

Butler, D. L. \& Cartier, S. C. (2005). Multiple complementary methods for understanding selfregulated learning as situated in context. Annual conference of the American Educational Research Association, Montreal, Quebec. http:/ / ecps.educ.ubc.ca/sites/ecps.educ.ubc.ca/files/upl oads / zzz/SPED / Butler_ConfPapers/Butler\%20\%20Cartier\%202005\%20AERA\%20Paper\%20Final.pdf

Cartwright, S. (2005). Resource based learning. [viewed 14 Sep 2010; not found 1 Mar 2012]] http:/ / www.adelaidehs.sa.edu.au/rblweb/rblsue.html

Chang, C. S., Chen, T. S., \& Hsu, W. H. (2010). The study on integrating WebQuest with mobile learning for environmental education. Computers \& Education, 57(1), 1228-1239. http:/ / dx.doi.org/10.1016/j.compedu.2010.12.005

Cohen. J. (1988). Statistical power analysis for the behavioral sciences (2nd ed.). Hillsdale, NJ: Lawrence Erlbaum.

Çigrik, E. \& Ergül, R. (2010). The investion effect of using WebQuest on logical thinking ability in science education. Procedia - Social and Behavioral Sciences, 2(2), 4918-4922. http: / / dx.doi.org/10.1016/j.sbspro.2010.03.795

Cureton, E. E. (1957). The upper and lower twenty-seven per cent rule. Psychometrika, 22(3), 293296. http:/ / dx.doi.org/10.1007/BF02289130

Dodge, B. (1995). Some thoughts about WebQuests. [viewed 13 Sep 2010, verified 1 Mar 2012] http: / / webquest.sdsu.edu/about_webquests.html

Dodge, B. (2001). FOCUS: Five rules for writing a great WebQuest. Learning and Leading with Technology, 28(8), 6-9. http: / / business.highbeam.com/4240/article-1G1-74336587 / focus-fiverules-writing-great-webquest

Dodge, B. (2002). WebQuest taskonomy: A taxonomy of tasks. [viewed 14 Oct 2010, verified 1 Mar 2012] http:/ / webquest.sdsu.edu/ taskonomy.html

Gottman, J. M. \& Roy, A.K. (1990). Sequential analysis: A guide for behavioral researchers. Cambridge University Press: Cambridge.

Kurt, S. (2010). WebQuests and Web 2.0 screen design. Journal of Technology in Human Services, 28(3), 178-187. http: / / www.tandfonline.com/doi/abs/10.1080/15228835.2010.508366 
Sanford, J., Townsend-Rocchiccioli, J., Trimm, D. \& Jacob, M. (2010). The WebQuest:

Constructing creative learning. Journal of Continuing Education in Nursing, 41(10), 473-479.

http: / / www.slackjournals.com/article.aspx?rid=64024

Segers, E. \& Verhoeven, L. (2009). Learning in a sheltered Internet environment: The use of WebQuests. Learning and Instruction, 19(5), 423-432.

http:/ / www.sciencedirect.com/ science/article/pii/S0959475209000188

Shin, K. P., Chen, H. C., Chang, C. Y. \& Kao, T. C. (2010). The development and implementation of scaffolding-based self-regulated learning system for e/m-learning. Educational Technology E Society, 13(1), 80-93. http:/ / www.ifets.info/download_pdf.php?j_id=46\&a_id=1020

Vygotsky, L. S. (1978). Mind in society: The development of higher psychological processes. Cambridge: Harvard University Press.

WebQuest (2007). WebQuest.Org. http:/ / webquest.org/

Zacharia, Z. C., Xenofontos, N. A. \& Manoli, C. C. (2011). The effect of two different cooperative approaches on students' learning and practices within the context of a WebQuest science investigation. Educational Technology Research and Development, 59(3), 399-424. http: / / www.springerlink.com/ content/a22470774w964350 /

Zimmerman, B. J., Bonner, S. \& Kovach, R. (1996). Developing self-regulated learner: Beyond achievement to self-efficacy. Washington, DC: American Psychological Association.

Zimmerman, B. J. \& Kitsantas, A. (2002). Acquiring writing revision and self-regulatory skill through observation and emulation. Journal of Educational Psychology, 94(4), 660-668. http: / psycnet.apa.org/journals/edu/94/4/660/

Authors: Professor Hsien-Sheng Hsiao (author for correspondence), Chung-Chieh Tsai and Chien-Yu Lin, Department of Technology Application and Human Resource Development

National Taiwan Normal University, no. 162, Sec. 1, Hoping East Rd., Taipei, Taiwan Email: hssiu@ntnu.edu.tw, jellen_tsai@hotmail.com,897710024@ntnu.edu.tw

Chih-Cheng Lin, Department of English

National Taiwan Normal University, no. 162, Sec. 1, Hoping East Rd., Taipei, Taiwan Email: cclin@ntnu.edu.tw

Please cite as: Hsiao, H. S., Tsai, C. C., Lin, C. Y. \& Lin, C. C. (2012). Implementing a self-regulated WebQuest learning system for Chinese elementary schools. Australasian Journal of Educational Technology, 28(2), 315-340.

http: / / www.ascilite.org.au/ajet/ajet28/hsiao-hs.html 